use services outside the home; (e) assistance with home adaptations; $(f)$ holiday facilities; $(g)$ meals at home or elsewhere; and (h) a telephone or any special equipment necessary for its use. This section, like Section 1, does not apply to Scotland. The Social Work (Scotland) Act, 1968 is obviously not providing similar support, and it remains to be seen how effective the 1970 Act is in England and Wales. Many of the facilities listed above were available but there were many patients in need. In normal circumstances $74 \%$ ownership of telephones would be high (the Family Expenditure Survey for 1968 showed only $29 \%$ of British households having this amenity (Department of Employment, 1971)), but Section 2 of the 1970 Act recognizes the telephone as an essential facility for the disabled. Perhaps the most significant indication of social deprivation is the difficulties over holidays and transport experienced by many in this series.

Problems such as these are to be found on a wide scale throughout Great Britain. From a survey of the handicapped and impaired in a quarter of a million households it was estimated that although three out of four drew on at least one service there remained 2,000 very severely handicapped and 90,000 others who were living alone and not receiving services (Buckle, 1971). A writer reviewing that survey found consolation in the Chronically Sick and Disabled Persons Act and commented that the situation shown in the report might soon be improved as a result of it (Lancet, 1971). We are concerned that improvement is less assured in Scotland, where the provision of these services is not guaranteed by legislation.

Other sections of the Act apply to Scotland. Section 3, for example, lays a new duty on local authorities to consider the particular needs of the chronically sick and disabled when planning the provision of housing. Special houses are to be distinguished in planning proposals. Such provision would be very useful, as local authority provision of purpose-built housing in the area covered by the present survey was very limited and none of the paraplegics occupied such accommodation.

In examining the social consequences of paraplegic in Scotland we have had the advantage of studying a group of patients with obvious disability. We would suggest that the difficulties in obtaining employment and social services may be greater for subjects with less clearly defined disability.

We thank the paraplegics for their co-operation and Miss G. Bowie for help with the survey. We also wish to thank Sister L. MacQueen, Miss M. Lloyd, and Mr. A. MacDougall (Philipshill Hospital, Glasgow). Mrs. M. Thompson (Edenhall Hospital, Edinburgh), and Mr. J. Laird (Scottish Paraplegic Association) for help. Mr. Duncan Guthrie and Professor J. A. Simpson gave encouragement, and I.B.M. (U.K.) Ltd. provided financial support.

\section{References}

Buckle, J. R. (1971). Office of Population Censuses and Surveys. Handicapped and Impaired in Great Britain, Part II. London, H.M.S.O. Department of Employment (1971). British Labour Statistics Yearbook, 1969, Table 194. London, H.M.S.O.

Forder, A., Reti, T., and Silver, J. R. (1969). Social and Economic Administration, 3,3 .

Gehrig, R., and Michaelis, L. S. (1968). Paraplegia, 6, 93.

Guttmann, L. (1962). Rehabilitation, 43, 9.

Guttmann, L. (1965). In Trends in Social Welfare, ed. J. Farndale, p. 319. Oxford, Pergamon Press.

Guttmann, L. (1967). Paraplegia, 5, 115.

Rancet, 1971, 1, 1169. Paraplegics Report for Liverpool Regional Hospital Board.

Robinson, E. S. (1970). Survey of Employment for Quadriplegics. National Spinal Injuries Centre, Stoke Mandeville Hospital, Aylesbury, Buckinghamshire. Privately circulated.

Siegel, M. S. (1969). In Proceedings of 17th Veterans Administration Spinal Cord Injury Conference, New York p. 230. New York, Veterans Administration

Thompson, M. A., and Murray, W. A. (1967). Paraplegia at Home: A Pilot Survey. Edinburgh, Livingstone.

\title{
"Capillary Permeability" in Patients with Collagen Vascular Diseases
}

\author{
JANET MARKS, D. A. BIRKETT, SAM SHUSTER
}

British Medical fournal, 1972, 1, 782-784

\section{Summary}

"Capillary permeability" to serum albumin has been measured in patients with collagen vascular diseases by a method which compares the dilution of intravenously injected ${ }^{131} I-h u m a n$ serum albumin and ${ }^{51}$ Cr-R.B.C.S. The results indicate an increased capillary permeability comparable to that which occurs in patients with extensive inflammatory skin disease. We suggest that this increased capillary permeability may be the cause of the episodes of oedema which occur in patients with collagen vascular diseases such as disseminated lupus erythematosus, systemic sclerosis, dermatomyositis, polyarteritis nodosa, and rheumatoid arthritis. "Spontaneous periodic oedema" may be the presenting feature of collagen vascular disease and is due to increased capillary permeability.

University Department of Dermatology and Wellcome Laboratories for Research into Skin Disease, Royal Victoria Infirmary, Newfor Research into Skin Dis
castle upon Tyne NE1 4LP

JANET MARKS, D.M., M.R.C.P., Senior Lecturer

D. A. BIRKETT, M.B., B.CHIR., M.R.C.P., Consultant Dermatologist, Teesside, Darlington, and Northallerton Hospitals. (Present address: Carter Bequest Hospital, Middlesbrough)

SAM SHUSTER, PH.D., F.R.C.P., Professor of Dermatology

\section{Introduction}

People with disseminated lupus erythematosus, systemic sclerosis, dermatomyositis, polyarteritis nodosa, and rheumatoid arthritis may have oedema. This is not always explicable on the basis of heart failure, renal or hepatic involvement, hypoalbuminaemia, or treatment with fluid-retaining drugs, and it is not always limited to areas clinically affected by the disease process. It occurred to us that it might be due to increased "capillary permeability" as in patients with erythroderma, and we therefore set out to test this hypothesis.

\section{Patients and Methods}

Patients with various collagen vascular diseases were asked if they would agree to take part in the investigation. The diagnoses were made on the usual clinical and laboratory grounds. Although patients with disease of all degrees of severity were included, most of them were in hospital and therefore more than mildly affected; moreover, colleagues who knew of our interest in oedema may have tended to refer, particularly, albeit unconsciously, the oedematous patients to us. The patients who had unexplained oedema at the time of the investigation are indicated in Fig. 2 but a few of the remainder gave a history of one or more episodes of swelling in the past. The degree of oedema varied from a little bilateral ankle swelling to severe generalized oedema. No patients who had 
recently been treated with intravenous low-molecular-weight dextran were included in the study.

Capillary permeability was measured by the method previously described by us (Marks and Shuster, 1966). It is based on the comparison of $(\mathrm{A})$ plasma volume measured by dilution of ${ }^{131}$ I-human serum albumin (H.S.A.) and (B) plasma volume calculated from ${ }^{51} \mathrm{Cr}$-erythrocyte (R.B.C.) volume and "wholebody" packed cell volume. The principle of the method is that A will be an overestimate of true plasma volume in any condition in which there is an increased leakage of serum albimun from the intravascular compartment, while B will not. We can therefore calculate the percentage of the plasma volume leaking out from the plasma compartment as $(\mathrm{A}-\mathrm{B}) \div \mathrm{B} \times 100$.

In practice, the time between the injection of the ${ }^{131}$ I-H.S.A. and the taking of the sample of blood for measurement of ${ }^{131} \mathrm{I}-$ H.S.A. dilution in plasma is 10 minutes, and the percentage of the plasma volume "lost" in this time by extravascular dilution is an index of capillary permeability (Marks and Shuster, 1966). In the calculation of $\mathrm{B}$ from the dilution of ${ }^{51} \mathrm{Cr}$-R.B.C.s the whole-body packed cell volume was obtained from the venous packed cell volume by multiplying it by 0.91 to allow for the different distribution of cells and plasma within the differentsized vessels (Chaplin et al., 1953).

Although we use the term "capillary" because this is the conventional terminology, it is not intended to indicate the precise anatomical site at which the protein leak takes place, and this is thought to be in the small venules (Aschheim, 1965), nor have we used "permeability" in its strict physical sense.

The patients with collagen vascular diseases were compared with two other groups of patients: (1) those with minimal skin disease, mostly eczema or psoriasis of limited extent, who acted as a control group, and (2) those with erythroderma-that is, inflammatory disease of the skin, usually eczema or psoriasis, involving $100 \%$ body surface, and who as a group have already been shown to have increased capillary permeability to serum albumin (Marks and Shuster, 1966).

\section{Results}

Fig. 1 shows that capillary permeability to serum albumin was increased in the group of patients with various collagen vascular diseases, and that this increase was significant when compared with the capillary permeability in the control group of patients

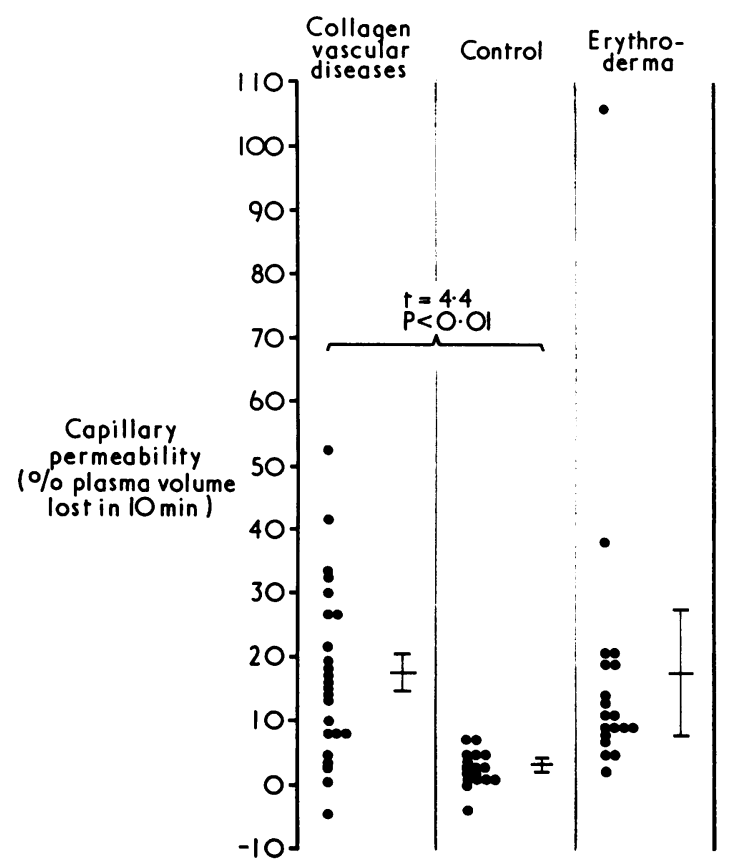

FIG. 1-Capillary permeability in patients with collagen vascular diseases and erythroderma and in a control group with localized skin disease. Mean and standard error are shown for each group. with localized skin disease $(t=4.4, P<0.01)$. The increase above normal is of the same order as that in the group of patients with erythroderma $(t=2.8, \mathrm{P}<0.01)$ (Fig. 1). Fig. 2 shows the results in the various collagen vascular disaeses separately. Twenty patients with disseminated lupus erythematosus, systemic sclerosis, dermatomyositis, and rheumatoid arthritis had an increased capillary permeability, though in three this increase was marginal. Capillary permeability was increased in some patients who had no oedema at the time of study.

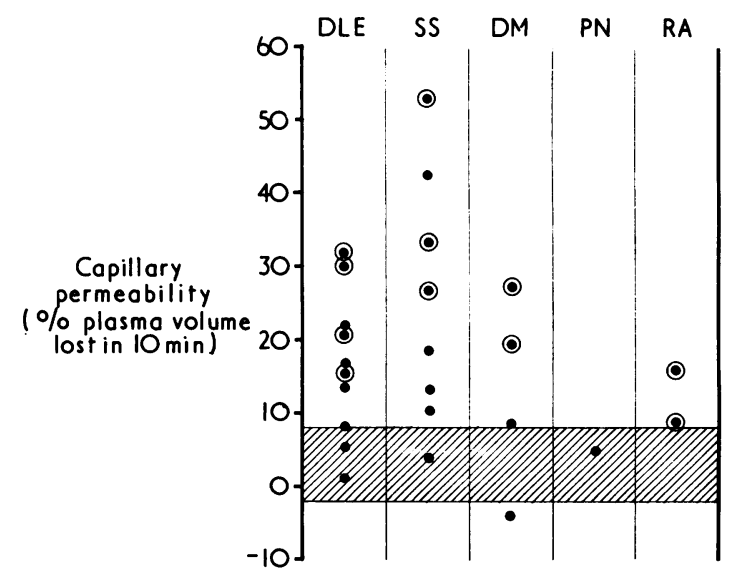

FIG. 2-Capillary permeability in the individual collagen vascular diseases, disseminated lupus erythematosus, systemic sclerosis, dermatomyositis, polyarteritis nodosa, and rheumatoid arthritis. Open circles indicate patients with oedema at the time of the test. Shaded area indicates the range for the control group.

\section{Discussion}

The present results in patients with erythroderma confirm our previous finding of a great increase in capillary permeability to serum albumin in this condition (Marks and Shuster, 1966). The increased capillary permeability explains the common clinical finding of oedema and the less common clinical syndrome of collapse with rapidly increasing dermal oedema, hypovolaemia, and hypoalbuminaemia (Zak and Pai, 1968; Shuster and Marks, 1970).

The results in patients with the various collagen vascular diseases likewise suggest an appreciable increase in capillary permeability in these conditions. An alternative explanation of the findings would be a decrease of the R.B.C. content of blood in the capillary bed so that the ratio of venous to whole-body packed cell volume is changed. This explanation can be rejected since if the volume of blood in the small vessels is $20 \%$ of the intravascular volume (Gibson et al., 1946) the observed increases in capillary permeability could be achieved only by a peripheral circulation completely devoid of red cells. Moreover, the evidence from direct microscopy of peripheral vessels, such as nailfold capillaries, in the collagen vascular disorders is to the contrary as there is sludging of R.B.C.s. We can conclude therefore that capillary permeability to albumin is increased in patients with various collagen vascular diseases, although we are unable to entirely exclude the contribution of some change in red cell and plasma distribution. It is interesting that by using an entirely different method other workers have shown an increase in capillary permeability in patients with rheumatoid arthritis (Jayson and Barks, 1971).

The relation of the increased capillary permeability to clinical oedema is of interest. Our patient with the grossest oedema, who had systemic sclerosis with pitting oedema of the arms, legs, face, and chest wall, also had the greatest increase in capillary permeability of any patient with a collagen vascular disease $(+53 \%$, Fig. 2). All the patients who had oedema had an increased capillary permeability although in most of them the oedema was slight. Some had no oedema although capillary permeability was increased; these patients were presumably able to compensate for the increased capillary leak by an in- 
creased resorption of tissue fluid, for oedema will occur only when there is no longer a state of equilibrium between the two.

We have previously noticed transient and otherwise unexplained episodes of bilateral oedema of various degrees of severity in patients with disseminated lupus erythematosus, systemic sclerosis, dermatomyositis, polyarteritis nodosa, and rheumatoid arthritis, and spontaneous periodic oedema was the presenting feature in two patients, one with disseminated lupus erythematosus and one with dermatomyositis. The capillary permeability in these patients was $+16 \%$ and $+19 \%$ respectively (Fig. 2).

Unexplained oedema, whether chronic or "spontaneous periodic," should raise the possibility of increased capillary permeability due to an underlying collagen vascular disease, and we suggest that such patients should be investigated with this in mind.
This work was carried out while we were in receipt of a grant from the Medical Research Council and we are grateful for this. We are also grateful to Professor F. T. Farmer and his staff for advice about the isotope studies, and to the doctors who referred patients to us.

\section{References}

Aschheim, E. (1965). Federation Proceedings, 24, 1104.

Chaplin, H., Mollinson, P. L., and Vetter, H. (1953). Fournal of Clinical Investigation, 32, 1309.

Gibson, J. G., et al. (1946). Fournal of Clinical Investigation, 25, 848

Jayson, M. I. V., and Barks, J. S. (1971). British Medical fournal, 2, 555

Marks, J., and Shuster, S. (1966). British Medical fournal, 2, 88. Marks, J., and Shuster, S. (1966). British Medical fournal, 2, 88.

Zak, F. G., and Pai, S. H. (1968). Fournal of the American Medical Association, 206, 1087.

\title{
Brown Nail-bed Arcs and Chronic Renal Disease
}

\author{
W. K. STEWART, E. J. RAFFLE
}

British Medical fournal, 1972, 1, 784-786

\section{Summary}

A brown arc affecting the distal part of the fingernail-bed, just proximal to the point of separation of the nail from its bed, has been found in 12 out of 34 patients with chronic renal disease $(35 \%)$ compared with an incidence of less than $2 \%$ in a series of unselected patients. It represents a distinctive form of pigmentation, possibly due to lipochromes. No decisive association could be found between the presence or absence of the pigmented nail arc and the level of impaired renal function. Nevertheless it seems that renal disease predisposes towards the development of brown nail arcs.

\section{Introduction}

The significance of a brown arc set across the distal part of the fingernails and toenails proximal to the line of separation of the nail plate from the bed (see Fig.) is not generally recognized. There is little mention of this clinical sign since its first description by Bean (1962). The standard monograph on nail disorders (Samman, 1965) does not refer to such arcs, nor are they mentioned in discussions of skin manifestations of systemic

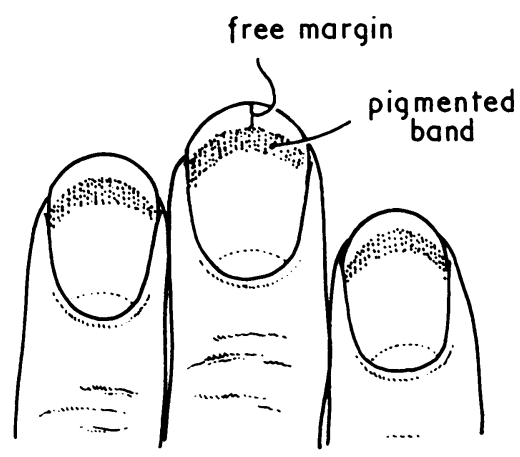

Diagrammatic distribution of brown arcs.

University of Dundee, Dundee DD1 4HN

W. K. STEWART, M.B., CH.B., F.R.C.P., Senior Lecturer in Medicine E. J. RAFFLE, M.B., CH.B., F.R.C.P., Consultant Dermatologist disease (Andrews and Domonkos, 1963; Rook et al., 1968; Braverman, 1970). Lindsay (1967) described a condition of similar appearance which he termed "the half-and-half nail," and there has been an isolated case report (Baran and Gioanni, 1968). Bean (1962), Lindsay (1967), and Baran and Gioanni (1968) all related the nail lesion to associated renal disease and azotaemia. We have measured the prevalence of pigmented arcs among unselected hospital patients and among patients attending a renal clinic and attempted to relate the presence of arcs to the orthodox clinical and biochemical features of renal failure.

\section{Patients and Method}

Thirty-four patients attending a renal clinic over a three-month period were assessed in respect of their nails, skin, and renal function, the features noted being as listed in Table I. In addition, similar pigmented arcs were sought in all patients seen at our various clinics or in our wards during a one-year period.

TABLE I-Features Assessed

\begin{tabular}{|c|c|}
\hline Dermatological & Renal \\
\hline $\begin{array}{l}\text { Presence or absence of brown nail arc } \\
\text { Depth of arc } \\
\text { Colour of arc } \\
\text { Length of attached nail } \\
\text { Colour of remainder of nail-bed } \\
\text { Involvement of fingers and/or toes } \\
\text { Abnormal skin pigmentation } \\
\text { Pruritus } \\
\text { Other skin disorder }\end{array}$ & $\begin{array}{l}\text { Nature of chronic renal disease } \\
\text { Renal function: } \\
\text { Serum creatinine } \\
\text { Blood urea } \\
\text { Serum total proteins } \\
\text { Serum albumin } \\
\text { Degree of proteinuria } \\
\text { Grade of renal deficit } \\
\text { Presence of non-renal disease }\end{array}$ \\
\hline
\end{tabular}

\section{Results}

Of the 34 patients with established chronic renal disease 12 $(35 \%)$ were found to have a brown arc of varying degree and 22 showed no nail abnormality (Table II). The intensity and depth (between 1 and $7 \mathrm{~mm}$ ) varied from patient to patient. There was no associated onycholysis, and the remainder of the nail-bed was either a normal colour or showed the pallor of anaemia, in which case the lunulae were rendered inconspicuous. Ten of the 12 affected patients had a well-defined brown arc on the toenails also, but in most patients the toenails were so 